\title{
Reducing Phenolics Related to Bitterness in Table Olives
}

\author{
Rebecca L. Johnson and Alyson E. Mitchell \\ Department of Food Science and Technology, University of California, Davis, One Shields Avenue, Davis, CA 95616, USA \\ Correspondence should be addressed to Alyson E. Mitchell; aemitchell@ucdavis.edu
}

Received 21 May 2018; Revised 9 July 2018; Accepted 24 July 2018; Published 13 August 2018

Academic Editor: Amani Taamalli

Copyright (C) 2018 Rebecca L. Johnson and Alyson E. Mitchell. This is an open access article distributed under the Creative Commons Attribution License, which permits unrestricted use, distribution, and reproduction in any medium, provided the original work is properly cited.

\begin{abstract}
Olives are one of the oldest food products in human civilization. Over the centuries, numerous methods have been developed to transform olives from a bitter drupe into an edible fruit. Methods of processing table olives rely on the acid, base, and/or enzymatic hydrolysis of bitter phenolic compounds naturally present in the fruit into nonbitter hydrolysis products. Today, there are three primary methods of commercial table olive processing: the Greek, Spanish, and Californian methods, in addition to several Artisanal methods. This review focuses on the technological, microbiological, chemical, and sensory aspects of table olive processing and the inherent benefits and drawbacks of each method. The table olive industry is facing challenges of environmental sustainability and increased consumer demand for healthier products. Herein, we examine current research on novel technologies that aim to address these issues.
\end{abstract}

\section{Introduction}

The olive tree (Olea europaea L.) was first cultivated approximately 5000-6000 years ago in the early bronze age and is one of the oldest known cultivated plants [1]. Ripe olives contain high levels of bitter phenolic compounds including oleuropein and ligstroside that make the fruit inedible $[2,3]$. In order for olives to be considered suitable for human consumption, the fruit must undergo some form of processing, fermentation, or curing to reduce the concentration of these bitter phenolic compounds. Various methods are used worldwide to debitter olives. Many of these methods have roots in ancient antiquity (e.g., salt curing), while others employ recent technological developments (e.g., California black ripe processing).

Today, there are three main commercial approaches used for debittering olives which include Greek, Spanish, and California processing methods (Table 1; Figure 1). In addition, there are several artisanal methods used to produce table olives with limited industrial scalability (e.g., salt curing or air-dried olives). Each method of debittering produces a different style of table olives with a unique texture and chemical, microbial, and sensorial profiles.
The consumption of table olives increased globally by $182 \%$ [4], and olive oil consumption increased by $76 \%$ between 1990 and 2016 [5]. This increase is attributed to the popularity of the Mediterranean diet, which is linked to reducing cardiovascular disease [6], Alzheimer's disease $[7,8]$, and other age-related conditions [9]. Consumption of olive oil is an essential component of the Mediterranean diet due to presence of mono-unsaturated fatty acids and phenolic compounds that are unique to Olea europaea and exhibit antioxidant [10], anti-inflammatory [11], anticancer [12], antimicrobial, and antiviral properties [13, 14]. This phenolic fraction is also present in table olives. Current commercial table olive processing methods remove many of these bitter phenolic compounds and as a result, can alter the health-promoting potential of various table olive products $[15,16]$. Additionally, current commercial table olive processing methods are some of the most water intensive methods used in commercial food processing and can require more than 7,571 liters of water per ton of olives (e.g., California and Spanish methods) and generate highly toxic wastewater. Increased consumer demand for healthier food products that are produced in an environmentally sustainable manner, as well as industrial interest in 
TABle 1: Comparison of Greek natural, Spanish green, and California style black ripe table olives processing parameters.

\begin{tabular}{lccc}
\hline Method & Greek natural & Spanish green & Californian style black ripe \\
\hline Raw fruit & Purple maturation & Green maturation & Green maturation \\
Debittering mechanism & Diffusion & Base hydrolysis + diffusion & Base hydrolysis \\
Debittering time & $6-12$ months & $1-7$ months & 1 week \\
Final pH & $\sim 4$ & $\sim 4$ & $5.8-7.9$ \\
Final color & Purple or dark brown & Green or pale yellow & Black (artificial color) \\
Flavor & Salty, acidic, and fermented & Salty, acidic, and fermented & Soapy, earthy, and buttery \\
Wastewater per ton olive & $0.9-1.9 \mathrm{~m}^{3} / \mathrm{t}$ & $3.9-7.5 \mathrm{~m}^{3} / \mathrm{t}$ & $8.0 \mathrm{~m}^{3} / \mathrm{t}$ \\
Sterilization required & No & No & Yes \\
Drawbacks & Long processing time & - & Carcinogenic acrylamide \\
\hline
\end{tabular}

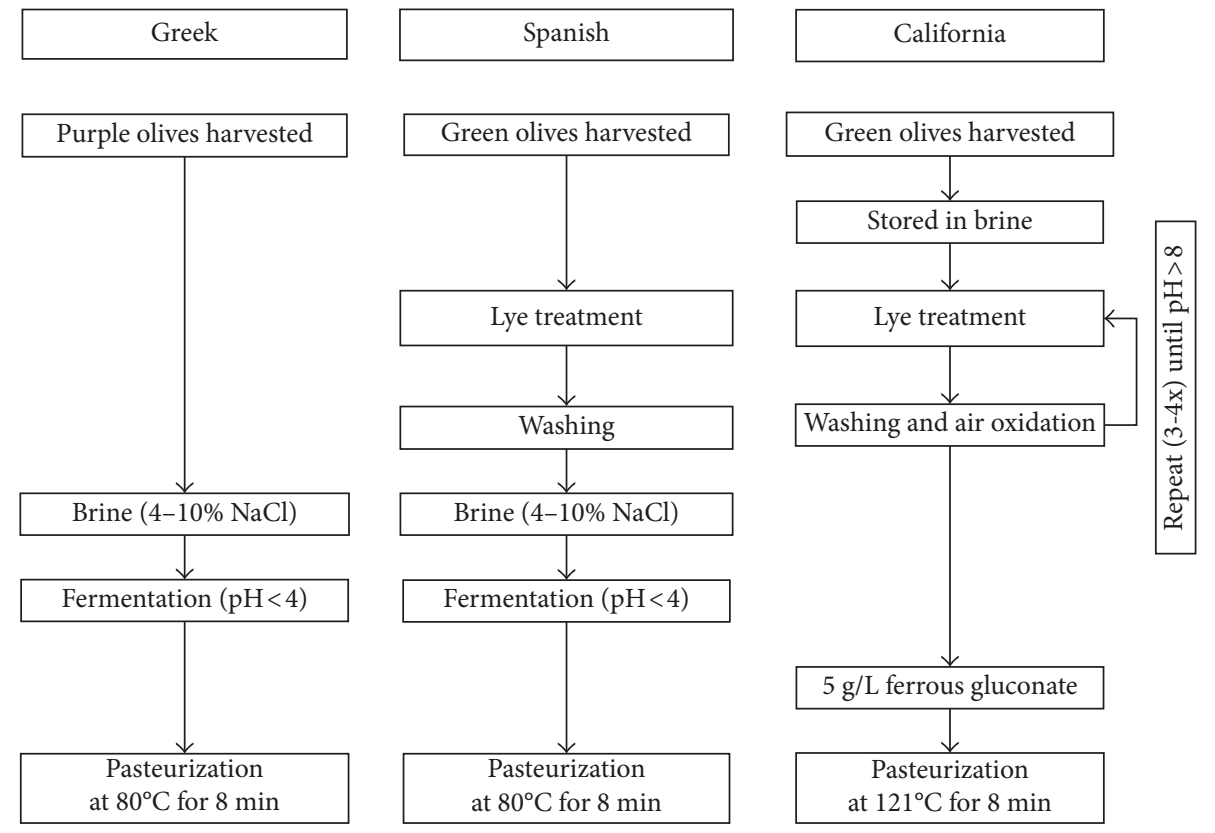

FIGURE 1: Diagram of Greek natural, Spanish green, and California style black ripe table olives processing methods.

decreasing processing time, water usage, and cost, demonstrates the need for innovation in olive processing technologies. This review focuses on the technological, microbiological, chemical, and sensory aspects of table olive processing, including the benefits and drawbacks of each processing method, and examines proposed novel technologies to improve table olive quality and industry sustainability.

\section{Olive Fruit Maturation}

Olive fruits are spherical or oval drupes, classified as small (less than 3 grams), medium (3-5 grams), or large (over 5 grams) [17]. During growth, olive drupes are green, and they accumulate bitter phenolics including oleuropein and ligstroside within the flesh and skin. Oleuropein and ligstroside are secoiridoids (i.e., a subclass of monoterpenoid iridoid compounds) that accumulate in the flesh and skin of olives as a protective mechanism against insect, pathogen, and herbivore attack (Figure 2) [18].

Green olives undergo three maturation stages on the tree which include (1) the green stage, (2) the turning color stage, and (3) the purple stage [17]. Color change occurs as the compounds that contribute to the green color in olives decrease (i.e., chlorophylls and carotenoids) and the compounds that contribute to red and purple colors increase (i.e., anthocyanins) [19]. As olives transition from green to purple, the cell wall of the fruit begins to rupture, softening the texture, and releasing enzymes, including the endogenous $\beta$-glucosidases and esterases [20, 21]. Endogenous enzymes within the olive fruit hydrolyze oleuropein and ligstroside into derivative compounds (i.e., oleuropein aglycone, ligstroside aglycone, oleocanthal, oleacein, hydroxytyrosol, tyrosol, oleoside methyl ester, and elenolic acid) that can then themselves be further hydrolyzed [22]. (Figure 2) As a result, the phenolic profile of green stage olives is different than purple stage olives, with the former containing a higher concentration of bitter phenolics [23, 24]. Although the purple olive fruit is less bitter than the green, both green and purple fruit of most varieties are far too bitter to be consumed raw without some form of processing or curing to reduce levels of these bitter phenolic compounds.

The olive fruit intended for table olive processing can be picked at any time during the maturation cycle, and olives intended for Greek fermentation, salt curing, or air drying 


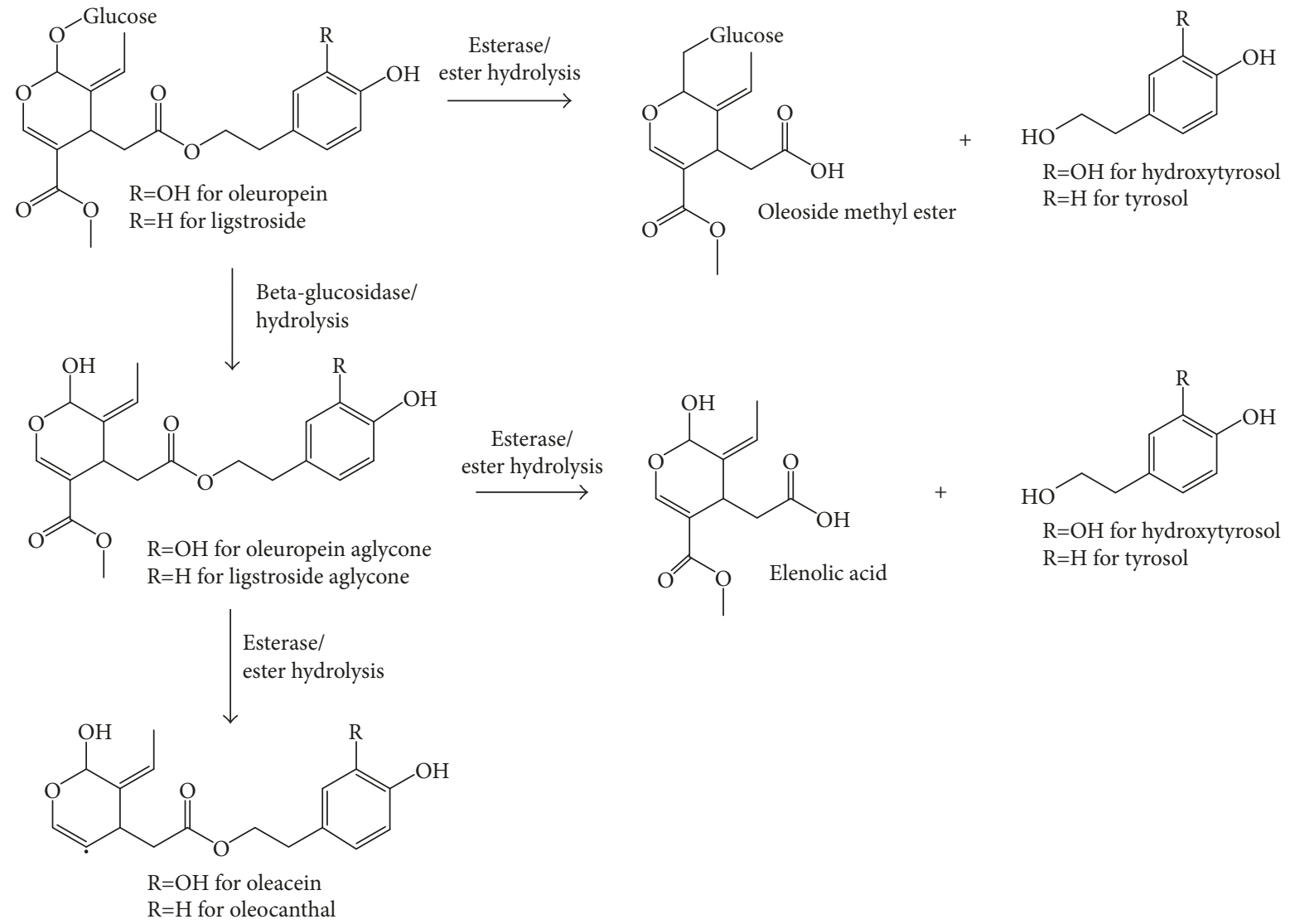

FIGURE 2: Olive secoiridoids and their hydrolysis products.

are generally harvested when purple, whereas olives intending for Spanish and California processing methods are harvested in the green stage [17]. Choice of the harvest stage will have an impact on the textural, sensorial, and chemical aspects of the final product.

\section{Phenolic Compounds in Olives}

Bitterness in raw olives is usually attributed to the presence of oleuropein, which is the most prevalent phenolics present at harvest [24]. However, oleuropein is not the only phenolic compound found in olives. Olive phenolics can be grouped into four broad categories: phenolic acids, phenolic alcohols, flavonoids, and secoiridoids [25]. While not all olive phenolics will contribute to olive bitterness, these compounds play an important role in the flavor profile, healthpromoting abilities, color, and shelf stability of table olives.

Phenolic acids $\left(\mathrm{C}_{6} \mathrm{C}_{1}\right)$ detected in olives include caffeic acid, $p$-coumaric acid, $o$-coumaric acid, ferulic acid, sinapic acid, syringic acid, hydroxybenzoic acid, dihydrocaffeic acid, vanillic acid, 3,4-dihydroxybenzoic acid, and gallic acid. Phenolic alcohols consist of a phenyl group $\left(-\mathrm{C}_{6} \mathrm{H}_{5}\right)$ bonded to a hydroxyl group $(-\mathrm{OH})$. Phenolic alcohols frequently detected in olive products include homovanillyl alcohol, hydroxytyrosol, and tyrosol. Flavonoids $\left(\mathrm{C}_{6} \mathrm{C}_{3} \mathrm{C}_{6}\right)$ frequently found in olives include luteolin-7-glucoside, cyanidin-3glucoside, cyanidin-3-rutinoside, rutin, apigenin-7-glucoside, quercetin-3-rhamnoside, and luteolin. Secoiridoids are phenolic compounds found in very few edible plants apart from olives and are among the more important compounds in regard to sensory perception of bitterness $[2,26]$. Secoiridoids are characterized by an exocyclic 8,9-olefinic functionality, comprised of an elenolic acid and a glucosidic residue, also known as an oleosidic skeleton. Notable secoiridoids in olives include oleuropein, ligstroside, and dimethyl oleuropein, as well as their phenolic derivatives and hydrolysis products, which include oleuropein aglycone, ligstroside aglycone, oleacein, and oleocanthal [25], compounds that are either known to be bitter or are considered likely bitter [27].

\section{Mechanisms for Debittering Olives}

Oleuropein, ligstroside, and related bitter phenolics can be reduced in table olives through several different mechanisms. Strong acids or bases can penetrate the olive flesh directly, where free $\mathrm{H}^{+}$and $\mathrm{OH}^{-}$ions catalyze the hydrolysis of oleuropein/ligstroside at the ester group that connects the hydroxytyrosol/tyrosol to the elenolic acid moiety. This hydrolysis reaction produces the nonbitter hydrolysis products oleoside methyl ester and hydroxytyrosol/tyrosol [2]. Olives flesh contains endogenous enzymes including $\beta$-glucosidase and esterase that can hydrolyze oleuropein at the ester bond between glucose and the elenolic acid moiety or between elenolic acid and hydroxytyrosol/tyrosol moiety [28]. Endogenous enzymes hydrolyze phenolic compounds within the fruit when the olive is still on the tree in response 
to maturation and damage, and hydrolysis continues during fermentation/processing unless inactivated by heat (Figure 2) [29].

During brine-based processing, bitter phenolics are removed from the olive by diffusing from the fruit into surrounding brine. Once these compounds have diffused into the brine, the acid and/or the enzymatic action of exogenous enzymes, $\beta$-glucosidase, and esterase from the microbiota present in the brine or surface of the olive can hydrolyze the phenolic compounds [30]. While phenolic compounds diffuse out of the olive, salt and acid from the brine diffuse in, changing the chemical and sensory profile of the product [31]. If the cellular structure of the olive is compromised, either by chemical (e.g., lye), physical (e.g., cracking, slitting, or destoning), or the natural biochemical softening, diffusion can occur more rapidly.

\section{Sensory Studies in Bitterness}

Sensory studies that examine bitterness in olive products have been conducted using either taste dilution analysis (TDA) or correlating bitterness of olive oil with semiquantitative concentration of measured phenolics [26, 32, 34]. TDA of oleuropein and oleuropein aglycone indicated that these compounds are bitter at a concentration of $50 \mu \mathrm{g}$ per $1 \mathrm{~cm}$ paper square [32]. TDA also confirmed that tyrosol was nonbitter, whereas oleacein, oleuropein aglycone, oleocanthal, ligstroside aglycone, and related isomers were described as bitter, astringent, or burning [33]. Although TDA is the preferred method for characterizing bitterness, it is not always possible due to the lack of commercial standards and the difficulty of isolating pure fractions of these phenolic compounds.

Sensory studies addressed these limitations by evaluating the bitterness of a wide range of olive products and correlating the individual phenolic concentrations obtained though semiquantitative methods to the perceived bitterness. While not ideal, these studies provide valuable information into which compounds are responsible for perceived bitterness in samples. From correlation studies, it can be inferred that oleuropein aglycone, ligstroside aglycone, oleacein, oleocanthal, elenolic acid, and elenolic acid methyl ester correlate well with bitterness perception [26]. Oleuropein and ligstroside derivatives, with the exception of tyrosol and hydroxytyrosol, are also reported as relative predictors of both static and dynamic analysis for bitterness and pungency, while ligstroside aglycone is effective only in predicting pungency [34].

\section{Main Commercial Methods}

6.1. Greek Fermentation Methods. Greek methods, typical to Mediterranean countries, use olives that are harvested when the fruit is close to full ripeness at the purple maturation stage (i.e., black ripe) but before the olives are overripened. Olives are washed and placed in an $8-10 \%$ sodium chloride brine solution (wt/vol) $[35,36]$. Fermentation is induced by indigenous microbiota present on the olives and in the environment. This method of debittering takes 6-12 months as it relies on diffusion into the brine to remove the bitter phenolics from the olive flesh $[35,36]$.

Once olives have achieved the bitterness and flavor profile desired by the producer, olives may be briefly exposed to oxygen to darken the skin via oxidation [36], and the color is stabilized with $0.1 \%$ ferrous gluconate [17]. This is done to correct for color losses due to the diffusion of anthocyanins into the brine during fermentation.

Greek olives are packed in cans or jars in a fresh solution of brine, acid, vinegar, or olive oil. Often these packing solutions are flavored by the addition of fennel, garlic, oregano, and other spices or flavoring agents [17]. The final product can vary in the bitterness level, flavor, texture, and taste depending on the length of fermentation, sodium chloride concentration of brine, and the microbiota present. Olive flavor is strongly influenced by the fermentation products including acids (e.g., lactic, acetic, and propionic acid) and alcohols (2-butanol and ethanol) [37]. Popular olives produced with this method include Kalamata (Kalamata variety) [38, 39], Nicoise (Cailletier variety) [40], Gaeta [41], Amfissa (Conservolea variety), Liguria (Taggiasca variety), Bitetto, and Nafplion green olives [40].

Olives produced using Greek methods are enjoyed and consumed all over the world. While bitterness in Greek olives can vary, studies indicate that these olives have higher levels of phenolic compounds as compared to those produced using Spanish processing methods [21]. The final $\mathrm{pH}$ of the brined olive is often low enough $(\sim 4)$ that olives do not need to be sterilized, although a pasteurization step may occur. Greek table olives may contain live cultures of lactic acid bacteria with probiotic potential for human health [42]. Although Greek processing methods are time-consuming, they use less water $\left(0.9-1.9 \mathrm{~m}^{3} /\right.$ ton olive $)$ than the Spanish or California processing methods and do not produce phenolic- and lye-enriched wastewater that requires specialized disposal [43].

6.2. Spanish Processing Methods. Spanish processing methods (a.k.a. Sevillian type) use olives picked at the green maturation stage and account for about $60 \%$ of the table olives produced worldwide [44]. These olives are immersed in lye for 8-10 hours to hydrolyze oleuropein. Lye treatment (2.0-5.0\% sodium hydroxide $\mathrm{NaOH}$ for $18-22$ hours) penetrates around two-thirds to three-quarters of the flesh, leaving a small area around the stone unaffected $[36,45]$. Olives are then rinsed with water ( $\mathrm{pH} 7.0)$ to remove excess lye and fermented in a brine that can range in sodium chloride concentration around $9-10 \% \mathrm{NaCl}$ but can drop do $4-5 \%$ due to olives high content of interchangeable water $[45,46]$.

During the initial lye treatment, oleuropein concentration decreases rapidly [47]. The lye solution penetrates the olive flesh where it hydrolyzes the oleuropein and ligstroside, producing nonbitter hydrolysis products such as hydroxytyrosol and tyrosol (Figure 1). In addition, the lye changes the composition of the polysaccharides in the cell wall structure decreasing firmness [48]. The higher the concentration of the lye and the longer the lye treatment, the greater the loss of firmness. The chemical damage to the olive skin and cell structure allows for a faster diffusion of the 
remaining olive phenolics and sugars into the brine during the subsequent rinsing and fermentation stages [31]. Lye changes the bacterial populations present both on the surface of the olive as well as in the brine, and a high $\mathrm{pH}$ can be an obstacle for desirable bacterial growth [49].

The water-rinsing step between the lye treatment and the fermentation is required to remove sodium hydroxide from the olive and reduce the $\mathrm{pH}$. Free phenolics and sugars will also be rinsed away during this step [43]. This is necessary as oleuropein and related olive phenolics act as inhibitors to desirable lactic acid bacteria growth, and rinsing helps remove phenolic compounds that may prevent the growth of this bacterium [48, 50]. Sugars also decrease during fermentation after a slight increase during the rinsing step [43].

Fermentation occurs through the action of naturally induced microbiota or through the addition of starter cultures. Olive phenolic loss continues during fermentation as phenolic compounds diffuse into the brine. Fermentation can take anywhere from 1-7 months depending on the variety [45].

The flavor of Spanish style green olives is greatly influenced by the presence of organic acids (e.g., lactic, acetic, and propionic) and alcohols formed during fermentation $[37,47]$. The main phenolic compounds in brine during Spanish method fermentation are hydroxytyrosol, elenolic acid glucoside, and tyrosol [47]. The final product is canned in a brine or acid solution which may contain additional flavoring agents. Olives processed using this method are often destoned, and the interior is replaced with an almond, pimento, or garlic slice. Olives are placed in cans or glass jars with fresh brine $(5-7 \% \mathrm{NaCl})$ at a low $\mathrm{pH}(<3.5)$. Common olive varieties processed into Spanish method olives include Manzanilla [51], Hojiblanca [51], Gordal [51], Picholine [52], Cerignola [53], and Belice olives [45].

Spanish processing methods are significantly faster than Greek fermentation methods (1-7 months versus 6-12 months), and the final product is firm in texture and green in color. Like Greek olives, Spanish olives can contain live strains of probiotics beneficial to human health [54]. The final $\mathrm{pH}$ is $\sim 4$, and therefore, these olives do not need to be sterilized but may be pasteurized. In contrast to the California and Greek style olives, the Spanish olives are not oxidized, and therefore, in-field bruising is more of a yield concern. The wastewater fraction is significant (3.9$7.5 \mathrm{~m}^{3} /$ ton olive) and includes a lye fraction that must be treated for disposal [43].

\subsection{Microbiota in Fermentation Brines for Greek and Spanish} Methods. There are similarities in the fermentation of Greek and Spanish olives. The microbiota present in the olive brine and on the olive epidermis has been extensively studied and can vary between olive producers due to differences in olive variety, sodium chloride concentration in brine, and oxygen exposure [55-57]. In general, there are three primary classes of microorganisms present in olive fermentation brines: Enterobacteriaceae, yeasts, and lactic acid bacteria [17]. Enterobacteriaceae, which grows naturally on the surface of olives through maturation, can only be found in the brine for the first 7-15 days of fermentation, after which they are no longer detectable, as the acidic conditions of the brine are not conducive to their growth [54]. Yeasts and lactic acid bacteria are the main microorganisms present in olive brines, but the ratio present can vary greatly depending on the sodium chloride concentration and oxygen exposure. Brines with higher sodium chloride concentrations $(>8 \% \mathrm{NaCl})$ will have a lower population of lactic acid bacteria, when compared to lower sodium chloride concentrations $(4-6 \% \mathrm{NaCl})[36,58]$. Both yeasts and lactic acid bacteria can contain exogenous $\beta$-glucosidases and esterases that can hydrolyze oleuropein, ligstroside, and other phenolic compounds that diffuse out of the olive and into the brine (Figure 3) [21].

If brine conditions are conducive to lactic acid bacteria growth, the $\mathrm{pH}$ of the brine will decrease during fermentation due to increases in lactic, acetic, and propionic acids [35]. The presence of propionic acid in the brines in considerable amounts indicates that the fermentation process was not controlled successfully and there is a high competition for limited nutrients by different microbial populations [59]. The decrease in $\mathrm{pH}$ helps to prevent the growth of spoilage and pathogenic microorganisms. The lactic acid bacteria fraction is made up of a diverse array of bacteria species that contribute to the acidity, flavor, and texture of the final product [57]. Sodium chloride and lactic, acetic, and propionic acids from the brine diffuse into the olive until equilibrium is reached [35]. Olives contain phenolic compounds that can inhibit lactic acid bacteria growth including oleuropein [60], oleuropein aglycone, elenolic acid, hydroxytyrosol [59], oleacein, and oleoside methyl ester [61]. Olive cultivars with high concentrations of oleuropein and related phenolics will have lower levels of lactic acid bacteria in fermentation brines, and yeast growth will dominate. The microbiota of yeasts present in fermentation brines is diverse, and numerous species have been identified in diverse green and black olive preparations [62]. Yeasts are an important component of fermentation as they may influence organoleptic characteristics of table olives including ethanol and other alcohols [47, 63].

If olives are brined in an anaerobic environment, a spoilage problem termed "floaters" can occur. Carbon dioxide builds up under the skin of the olive in response to olive respiration and growth of Gram-negative bacteria. This results in olives that float to the surface of the tank until the carbon dioxide is released, at which point the olive skin wrinkles with the appearance of blisters [64]. Texture defects in brined olives can occur with the growth of lipaseproducing yeasts $[65,66]$. Clostridia growth can cause butyric and putrid spoilage during the first few days of fermentation. A spoilage problem known as Zapateria can occur in the rising temperatures of spring and early summer. Zapateria results in an unpleasant taste and odor due to the production of cyclohexanecarboxylic acid and other volatile acids. A salt concentration above $8 \%$ and a pH below 4.2 helps prevent this problem [36].

6.4. California Black Ripe Processing Methods. The California black ripe processing method was developed in the late 


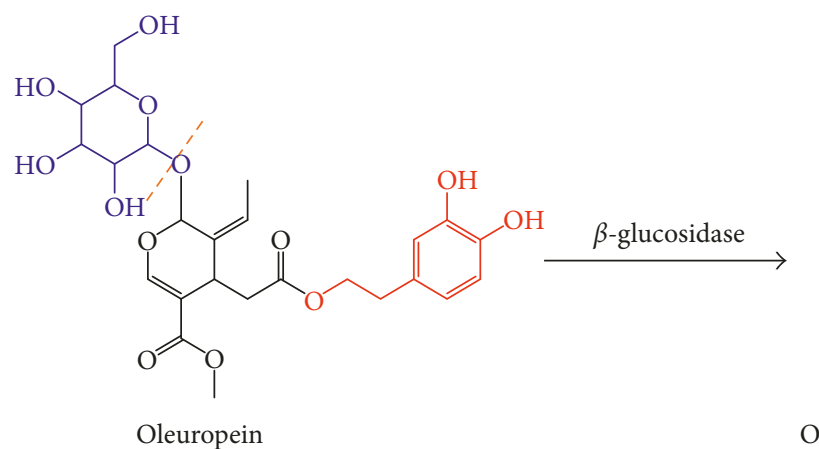<smiles>C/C=C1\C(O)OC=C(C(=O)OC)C1CC(=O)OCCc1ccc(O)c(O)c1</smiles>

Oleuropein aglycone

Glucose<smiles>CC=C1C(OC2OC(CO)C(O)C(O)C2O)OC=C(C(=O)OC)C1CC(=O)OI(I)CCc1ccc(O)c(O)c1</smiles>

Oleuropein<smiles>C/C=C1\C(OC2OC(CO)C(O)C(O)C2O)OC=C(C(=O)OC)C1CC(=O)O</smiles>

Oleoside methyl ester<smiles>OCCc1ccc(O)c(O)c1</smiles>

Hydroxytyrosol

FIgURE 3: Mechanism of oleuropein hydrolysis.

1800s by a Northern California homemaker, Freda Ehmann. Olives are picked at the green ripe or semiripe maturation stage and stored in salt or acidified brine for 3-12 months prior to processing. During brine storage, fermentation can occur through the growth of yeasts and lactic acid bacteria, and the phenolic content of the olives can be reduced through passive diffusion. Fermentation is not necessary to create these olives as the main action of debittering occurs through the use of lye (sodium hydroxide) [67]. Instead, olives are processed using a series (3-5) of lye treatments ( $\sim 0.5 \mathrm{M}$ sodium hydroxide) for several hours per treatment [65]. During the lye treatment, sodium hydroxide penetrates the olive flesh, hydrolyzing the olive phenolics and debittering the olives [68]. Anthocyanin concentration decreases during California lye processing [39]. Olives stored in a storage brine for longer periods of time do not need to be treated for as many lye cycles as freshly harvested olives do, and the strength and duration of lye cycles can vary between producers, variety, and season. During the lye treatment, texture changes can occur softening the olive cell walls and texture $[69,70]$.

In between lye treatments, olives are immersed in rinse water and oxidized with injected compressed air (i.e., oxygen is bubbled through the water) [17]. During oxidation, olives darken and turn brown as the phenolic compounds in the olive skin (predominantly hydroxytyrosol and caffeic acid) polymerize [71, 72]. Black ripe olives are considered debittered when the flesh next to the stone has a $\mathrm{pH}$ greater than 8 , as indicated by phenethylamine dye. Brown oxidized olives are then colored with the addition of ferric gluconate, which complexes with the compound hydroxytyrosol [68] and turns the fruit black [73].

Olives produced using the California method are packed in cans or glass jars with a salt brine or acidic solution. The final $\mathrm{pH}$ of the fruit can vary between 5.8 and 7.9. By FDA regulations, California black ripe olives must be legally sterilized at $115.6^{\circ} \mathrm{C}$ for $60 \mathrm{~min}$ or at $121.1^{\circ} \mathrm{C}$ for $50 \mathrm{~min}$ to prevent the growth of pathogenic bacteria [67]. The high temperature of sterilization can lead to the accumulation of the carcinogen, acrylamide, in olives [74, 75].

California black ripe table olives are made all over the world including Egypt, Morocco, Portugal, and Spain [76]. In the USA, they are consumed as popular toppings for pizza and tacos. The final canned product has a texture and profile very different from olives produced using Greek and Spanish methods. Sensory characteristics to describe California black ripe table olives include alcohol, oak barrel, artificial fruity/floral, buttery, salty, earthy, sour, and ocean-like aroma/flavor while defective olives can exhibit rancidity, metallic, gassy, and soapy/medicinal flavors [76]. American consumers showed a preference for domestic California olives as opposed to imported California black ripe olives [77]. Common olives used to produce California black ripe olives include Manzanillo [67], Hojiblanca [69], Mission [16], Intosso [68], and Sevillano varieties.

The California method produces table olives with the lowest levels of phenolic compounds, the mildest flavor, and the lowest consumer perception of bitterness when compared to other styles of olive [16]. In addition, the final $\mathrm{pH}$ of the Californian olives is higher than the Greek and Spanish 
olives and therefore more susceptible to pathogenic growth unless sterilized. The sterilization step can result in the formation of acrylamide [67]. The Californian method is highly water intensive and requires $8.0 \mathrm{~m}^{3} /$ ton of olive, of which $2.0 \mathrm{~m}^{3} /$ ton becomes the lye wastewater fraction [78].

6.5. California Green Ripe. California green ripe olives are a variant of the California black ripe olive that do not undergo oxidation (i.e., no compressed air during washing) and color fixation (e.g., ferric gluconate) [25]. This type of olive is processed from freshly harvested olives that have not been stored in a storage brine. The final product is similar in flavor and texture to California black ripe olives, but olives are in green color rather than black.

6.6. Italian Green Olives. Castelvetrano olives (i.e., Italian green olives) undergo a treatment that is cross between Spanish and California green ripe methods. Castelvetrano olives are made from the Nocellara del Belice variety and are large green olives that grow in central and southern Italy [45]. Only large fruits of more than $19 \mathrm{~mm}$ in diameter are processed into these table olives. Olives are placed in plastic vessels that contain $1.8-2.5 \%$ sodium hydroxide $(\mathrm{NaOH})$. An hour after the lye treatment begins, salt is added to the alkaline solution. Olives are held in the $\mathrm{NaOH} / \mathrm{NaCl}$ solution for 10-15 days [17]. After treatment, olives are washed to remove the lye, although a portion of the lye flavor remains and is enjoyed by consumers. As recently as 2012, it was discovered that many Italian olives cured in the Castelvetrano style were artificially colored green with E-141ii, copper chlorophyllin complexes, that is not a legally allowed additive for table olives or olive oil by the US Food and Drug Administration (FDA) and the European Union [79], and this continues to be a problem with food fraud today [80].

\section{Artesian Methods}

Several artesian methods exist which are less common in industrial settings but can be found associated with specific olive cultivars or regions. Because of space, size, and cost limitations, olives produced using water, salt/oil, and air/sun to aid in bitterness reduction are difficult to scale up in industrial settings.

7.1. Water Processing. Water processing methods share similarity with brining olives; however, the soaking water is salt-free, and no fermentation occurs. Olives intended for water processing are picked at any stage in maturation and placed in a large container of water which is then sealed. Bacterial populations are not controlled through acidity or salinity, and water is changed daily [81]. As a result, water processing is highly water intensive and easily susceptible to growth of spoilage and pathogenic bacteria. Water processed olives are usually only found in south of France or in-home kitchens. Destoning, slitting, or cracking open the olive will increase the diffusion rate and decrease the time required for debittering [82]. A low salt solution can be added for flavor, but no fermentation will occur.

Water processing is difficult to adapt to an industrial setting as the great volume of water used in the manufacturing process is cost prohibitive. Water-cured olives are often served in farmer's markets, local stores, and restaurants in salt brine solutions with flavoring agents such as lemon, oregano, vinegar, garlic, chilies, and olive oil. They are enjoyed for the fresh flavor, low acidity, and low salinity.

7.2. Salt/Oil Processing. Debittering olives using salt and oil is an old practice that uses no water. Olives are typically picked at the end of the purple maturation stage when the fruit is ready to fall off the tree. Olives are packed in drums in layers of dry salt for several weeks to several months. The salt removes moisture from the olive and allows a microbiota of yeasts, molds, and Enterobacteriaceae to form on the surface of the olive [83], which acts to prevent growth of pathogenic and spoilage bacteria [84].

Oleuropein, ligstroside, and related phenolic compounds are reduced within the olive though the action of endogenous enzymes, (e.g., $\beta$-glucosidase and esterase) that hydrolyze bitter phenolic compounds [29]. Olives are then removed from the dry salt layers, washed, and bathed in olive oil. Throuba olives from Crete (Thassos variety) are a popular table olive cured in this manner. Another variant on the salt processing method is the Beldi olive which is briefly treated with lye before being placed in barrels with layers of salt [83]. This processing method results in a wrinkly prunelike appearance, with a mushy texture and an intense concentrated flavor that can be highly bitter.

7.3. Air/Sun Processing. This is a natural method of reducing bitterness by leaving olives on the tree past maturation. Some varieties of olives, known as sweet olives, naturally reduce in the phenolic content while on the tree, and once they reach a low enough bitterness, the fruit can be eaten raw [85]. Olives are then sun-dried, and the final texture is wrinkly and the final flavor strong and intense. Olives that are typically left on the tree to reduce bitterness include Botija Peruvian black olives and Hurma Turkish sweet olives.

\section{Novel Technologies}

With the growing competitiveness in the international table olive market and changing consumer preferences for healthier products, alternative novel technologies are being explored for growing, harvesting, storage, and processing of table olives with the aim of decreasing processing time, decreasing water usage, improving sustainability, increasing the health properties of processed fruit, and decreasing production cost.

8.1. U.S. Table Olive Market. Table olive consumption in the US market has been in decline at an approximate rate of $-2.5 \%$ per capita consumption every year, while demand for 
olive oil is increasing at an approximate rate of $1.9 \%$ per capita consumption [86]. This is in part the perception of the American consumers that olive oil is healthy, while table olives are unhealthy [87]. Both olive oil and table olives contain healthy unsaturated fats and high levels of phenolics that have beneficial health properties. For that reason, olive oil is considered an important part of the Mediterranean diet, a diet linked to the reduction of heart disease and other age-related morbid conditions [6-9]. Additionally, the profit margin for producing table olives has decreased in the US due to rising water costs, labor costs, and lower price points as cheaper international products are available in the market. As a result, the California olive industry has shifted away from table olives to producing olive oil. Between 2000 and 2015 , olive processed into oil increased from $4 \%$ to $60 \%$ of all olives grown in California [88]. Another hurdle that table olive producers face is environmental sustainability. Olive processing is one of the most water intensive fruit or vegetable processing methods. Greek fermentation methods produce $0.9-1.9 \mathrm{~m}^{3} /$ tons of olive wastewater, Spanish methods 3.9-7.5 $\mathrm{m}^{3} /$ tons [43], and California methods $\sim 8.0 \mathrm{~m}^{3} /$ tons olive of wastewater, $2.0 \mathrm{~m}^{3} /$ ton olive of which becomes the lye wastewater fraction [78]. The wastewater that is produced is a dark effluent with high organic burden and polyphenol content that exhibits antibacterial properties. Releasing effluent streams directly into local water systems or on land can result in toxicological consequences and environmental contamination. Therefore, effluent streams are generally redirected to evaporation ponds. However, evaporating wastewater can create unpleasant aromas, and effluents carry the risk of polluting ground and surface water [89]. With ongoing environmental problems created by global warming, including sustained drought, water is becoming increasingly limited and costly. Proposed novel debittering technologies that can reduce water and lye usage and/or produce less toxic effluent streams will provide economic benefits and increase the sustainability of the industry.

Several novel debittering technologies are being considered and include the use of enzymes, resins, ultrasound, and vacuum among others. Most novel technologies focus on methods that remove phenolic compounds more quickly or efficiently and thereby reduce lye washes and the use of large amounts of water. Challenges remain with adapting new technologies to commercial processing without compromising table olive quality and are discussed below.

8.2. Ultrasound Debittering. The use of ultrasoundaccelerated debittering of the olive fruit has recently been examined [90]. When ultrasound is used in addition to lye treatments during California method debittering, the rate of phenolic reduction increased by $48 \%$. Ultrasound as a technique showed valorization in reducing the time and number of lye washes needed for debittering olives [90].

8.3. Vacuum Impregnation. Researchers at Uludag University (Bursa, Turkey) investigated the viability of using vacuum impregnation to speed up the rate of olive debittering. Olives treated under a vacuum of $68 \mathrm{kPa}$ demonstrated a shorter required processing time when compared to olives under atmospheric conditions. Green olives under vacuum impregnation and suspended in a lye treatment of $1.5 \% \mathrm{NaOH}$ took 8 hours to reduce the levels of oleuropein from starting conditions to a third of the initial concentrations, as compared to 48 hours under atmospheric conditions. In brined solutions of $3 \% \mathrm{NaCl}$, processing time decreased from 45 days under atmospheric pressure to 11 hours under vacuum impregnation [91].

8.4. Carbon Dioxide Overpressure. The influence of storing olives under a carbon dioxide overpressure on the phenolic content of raw table olives has also been investigated [92]. Green unripe olives were placed under a carbon dioxide overpressure for a period of twelve days and evaluated for bitterness by a trained sensory panel that compared treated olives to control olives exposed to atmospheric conditions. Olives under carbon dioxide overpressure turned red in color and decreased in bitterness without becoming dehydrated or shriveled. It was postulated that the decrease in bitterness was due carbon dioxide promoting the biosynthetic pathways that naturally occur with olives that remain on the branch, including the hydrolysis of oleuropein [92].

8.5. Oxygen Overpressure. Researchers at the University Pablo de Olavide (Sevilla, Spain) investigated a potential method of debittering olives under an overpressure of oxygen. Manzanilla olives stored in brine $(9 \% \mathrm{w} / \mathrm{v} \mathrm{NaCl}$ and $0.3 \% \mathrm{w} / \mathrm{v}$ acetic acid) for one month after harvest were exposed to an overpressure of 0.3 bars oxygen for 3 days. Oxidized fruit was then placed back in preservation brine for 6 months. Laboratory tests were variable (28-98\%) in the amount of oleuropein decreased. Olives exposed to an overpressure of oxygen became darker in color [93].

8.6. Enzymes. The use of exogenous $\beta$-glucosidase has also been explored as a method to reduce oleuropein [91]. Manzanilla olives were fermentation with inoculated $L$. plantarum, fermentation with inoculated $L$. plantarum and an extract of $\beta$-glucosidase, and cured using the traditional Spanish method of debittering. The phenolic content of the three treatments were measured, and trained sensory panelists scored the olives for texture, appearance, odor, aroma, bitterness and saltiness, and overall appreciation. The Spanish olives were observed to have the lowest bitterness and oleuropein concentration as compared to the inoculated and inoculated plus $\beta$-glucosidase treatments. Oleuropein concentration and bitterness perception were not significantly different between inoculated and inoculated $\beta$-glucosidase treatments. While $\beta$-glucosidase may hydrolyze oleuropein present in brines, under the conditions studied it was not enough to produce significant decreases in oleuropein or bitterness in the olive fruit [94].

8.7. Alternative Salt Solutions. The use of sodium, potassium, and calcium chloride salts to stabilize cell membranes during 
the fermentation step in Spanish olive debittering methods was also investigated [95]. Calcium salts can retard the diffusion of sugar from the olive into the brine during fermentation. This results in a decrease in lactic acid bacteria growth and lactic acid production. Lactic acid production is essential for the preservation and flavor of Spanish olives. The effect of alternative salt solutions on oleuropein concentration was not quantified, and therefore, the effect on debittering is unknown. The addition of calcium chloride to brine resulted in a firmer texture olive product as compared with the use of potassium and sodium salts [95].

8.8. ReTain Inhibition. Researchers at the Agricultural University of Athens (Athens, Greece) exposed olives on the tree to aminoethoxyvinylglycine (AVG) also known as ReTain which is an inhibitor of the enzyme 1-aminocyclopronane-1carboxylic acid synthase, a precursor to the production of ethylene, the plant hormone that stimulates ripening. Olives treated with ReTain demonstrated delayed ripening which extended the harvest, preventing color development and skin softening, while reducing oleuropein content [96].

8.9. Temperature Control. The use of ethylene oxide to delay ripening and promote the endogenous hydrolysis of oleuropein was also investigated [97]. Olives stored in closed container with $30 \mathrm{ppm}$ of ethylene at $40^{\circ} \mathrm{C}$ showed a significant reduction $(p \leq 0.05)$ of bitterness as well as pigment lost as compared to olives stored at $20^{\circ} \mathrm{C}$ with $30 \mathrm{ppm}$ ethylene. An unpleasant flavor was then observed in ethylene oxide-treated olives indicating that this is not a suitable method of table olive debittering [97].

8.10. Resin Debittering. Our group has investigated using polymeric resins to remove phenolic compounds from untreated olives during brine storage. Adsorptive resins (e.g., Amberlite ${ }^{\circledR}$ resins XAD4, XAD16N, XAD7HP, and FPX66) are nonreactive polymers that can adsorb phenolic compounds in a reversible manner so that adsorbed phenolics can be recovered as value-added products. Preliminary results demonstrate that all resins could remove oleuropein during brine treatments thereby significantly reducing olive bitterness without the need for additional processing.

8.11. Enrichment of Table Olive with Phenolics. With the aim of improving the nutritional value of table olives and creating a novel product (i.e., table olives enriched in olive phenolics), a group in Greece treated table olives with phenolic extracts from olive leaf [98]. Treatment increased the phenolic content of the table olives and also increased the consumer perception of bitterness [98].

\section{Conclusions}

Table olives are a popular food product consumed worldwide. While traditional and region-specific olive processing methods should be celebrated, there is the opportunity to develop new technologies for debittering olives, that will enable creation of novel products with new textures, flavors, and health-promoting properties that will appeal to contemporary consumers and expand markets. Novel technologies can also reduce water and labor costs and increase environmental sustainability.

\section{Conflicts of Interest}

The authors declare that there are no conflicts of interest regarding the publication of this paper.

\section{References}

[1] N. Liphschitz, R. Gophna, M. Hartmana, and G. Bigerh, "The beginning of olive (Olea europaea) cultivation in the old world: a reassessment," Journal of Archaeological Science, vol. 18 , no. 4, pp. 441-453, 1991.

[2] C. Soler-rivas, J. C. Esp1, and H. J. Wichers, "Review oleuropein and related compounds," Journal of the Science of Food and Agriculture, vol. 80, no. 7, pp. 1013-1023, 2000.

[3] G. Bianchi, "Lipids and phenols in table olives," European Journal of Lipid Science and Technology, vol. 105, pp. 229-242, 2003.

[4] 2017 International Olive Council Market Newsletter. No 112-January 2017.

[5] Flag Solutions, World Olive Oil Figures, Flag Solutions, International Olive Council, Flag Solutions, Salamanca, Spain, 2017.

[6] R. Estruch, R. Ros, J. Salas-Salvado et al., "Primary prevention of cardiovascular disease with a Mediterranean diet," New England Journal of Medicine, vol. 368, no. 14, pp. 1279-1290, 2013.

[7] V. Frisardi, F. Panza, D. Seripa et al., "Nutraceutical properties of Mediterranean diet and cognitive decline: possible underlying mechanisms," Journal of Alzheimer's Disease, vol. 22, no. 3, pp. 715-740, 2010.

[8] C. Féart, C. Samieri, B. Allès, and P. Barberger-Gateau, "Potential benefits of adherence to the Mediterranean diet on cognitive health," Proceedings of the Nutrition Society, vol. 72, no. 1, pp. 140-152, 2013.

[9] F. R. Pérez-López, P. Chedraui, J. Haya, and J. L. Cuadros, "Effects of the Mediterranean diet on longevity and agerelated morbid conditions," Maturitas, vol. 64, no. 2, pp. 67-79, 2009.

[10] F. Franconi, R. Coinu, S. Carta et al., "Antioxidant effect of two virgin olive oils depends on the concentration and composition of minor polar compounds," Journal of Agricultural and Food Chemistry, vol. 54, no. 8, pp. 3121-3125, 2006.

[11] L. Lucas, A. Russell, and R. Keast, "Molecular mechanisms of inflammation. Anti-inflammatory benefits of virgin olive oil and the phenolic compound oleocanthal," Current Pharmaceitical Design, vol. 17, no. 8, pp. 754-768, 2011.

[12] J. Han, T. P. N. Talorete, P. Yamada, and H. Isoda, "Antiproliferative and apoptotic effects of oleuropein and hydroxytyrosol on human breast cancer MCF-7 cells," Cytotechnology, vol. 59, no. 1, pp. 45-53, 2009.

[13] S. H. Omar, "Oleuropein in olive and its pharmacological effects,” Scientia Pharmaceutica, vol. 78, no. 2, pp. 133-154, 2010.

[14] F. Warleta, C. S. Quesada, M. Campos, Y. Allouche, G. Beltrán, and J. J. Gaforio, "Hydroxytyrosol protects against 
oxidative DNA damage in human breast cells," Nutrients, vol. 3, no. 10, pp. 839-857, 2011.

[15] G. Blekas, C. Vassilakis, C. Harizanis, M. Tsimidou, and D. Boskou, "Biophenols in table olives," Journal of Agricultural and Food Chemistry, vol. 50, no. 13, pp. 3688-3692, 2002.

[16] E. Melliou, J. A. Zweigenbaum, and A. E. Mitchell, "Ultrahigh-pressure liquid chromatography triplequadrupole tandem mass spectrometry quantitation of polyphenols and secoiridoids in California-style black ripe olives and dry salt-cured olives," Journal of Agricultural and Food Chemistry, vol. 63, no. 9, pp. 2400-2405, 2015.

[17] L. Rejano, A. Monta, F. J. Casado, A. Higinio, and A. D. Castro, Table Olives: Varieties and Variations, Elsevier Inc., New York, NY, USA, 2010.

[18] R. Mumm and M. Hilker, "Direct and indirect chemical defence of pine against folivorous insects," Trends in Plant Science, vol. 11, no. 7, pp. 351-358, 2006.

[19] M. Roca and M. Mínguez-Mosquera, "Changes in chloroplast pigments of olive varieties during fruit ripening," Journal of Agricultural and Food Chemistry, vol. 49, no. 2, pp. 832-839, 2001.

[20] I. Mafra, B. Lanza, A. Reis et al., "Effect of ripening on texture, microstructure and cell wall polysaccharide composition of olive fruit (Olea europaea)," Physiologia Plantarum, vol. 111, no. 4, pp. 439-447, 2001.

[21] V. Marsilio, L. Seghetti, E. Iannucci, F. Russi, B. Lanza, and M. Felicioni, "Use of a lactic acid bacteria starter culture during green olive (Olea europaea L cv Ascolana tenera) processing," Journal of the Science of Food and Agriculture, vol. 85, no. 7, pp. 1084-1090, 2005.

[22] H. Jemai, M. Bouaziz, and S. Sayadi, "Phenolic composition, sugar contents and antioxidant activity of tunisian sweet olive cultivar with regard to fruit ripening," Journal of Agricultural and Food Chemistry, vol. 57, no. 7, pp. 2961-2968, 2009.

[23] D. Ryan, P. Prenzler, S. Lavee, M. Antolovich, and K. Robards, "Quantitative changes in phenolic content during physiological development of the olive (Olea europaea) cultivar Hardy's mammoth," Journal of Agricultural and Food Chemistry, vol. 51, no. 9, pp. 2532-2538, 2003.

[24] M. J. Amiot, A. Fleuriet, and J. J. Macheix, "Importance and evolution of phenolic compounds in olive during growth and maturation," Journal of Agricultural and Food Chemistry, vol. 34, no. 5, pp. 823-826, 1986.

[25] S. Charoenprasert and A. Mitchell, "Factors influencing phenolic compounds in table olives (Olea europaea)," Journal of Agricultural and Food Chemistry, vol. 60, no. 29, pp. 7081-7095, 2012.

[26] G. Dierkes, S. Krieger, R. Dück, A. Bongartz, O. J. Schmitz, and H. Hayen, "High-performance liquid chromatographymass spectrometry profiling of phenolic compounds for evaluation of olive oil bitterness and pungency," Journal of Agricultural and Food Chemistry, vol. 60, no. 31, pp. 75977606, 2012.

[27] R. Mateos, A. Cert, M. C. Pérez-Camino, and J. M. García, "Evaluation of virgin olive oil bitterness by quantification of secoiridoid derivatives," Journal of the American Oil Chemists' Society, vol. 81, no. 1, pp. 71-75, 2004.

[28] C. Romero-Segura, C. Sanz, and A. G. Perez, "Purification and characterization of an olive fruit $\beta$-glucosidase involved in the biosynthesis of virgin olive oil phenolics," Journal of Agricultural and Food Chemistry, vol. 57, no. 17, pp. 7983-7988, 2009.

[29] E. Ramírez, M. Brenes, P. García, E. Medina, and C. Romero, "Oleuropein hydrolysis in natural green olives: importance of the endogenous enzymes," Food Chemistry, vol. 206, pp. 204-209, 2016.

[30] E. Medina, E. Ramírez, M. Brenes, and A. Castro, "Oleuropein hydrolysis by lactic acid bacteria in natural green olives," LWT-Food Science and Technology, vol. 78, pp. 165-171, 2017.

[31] M. B. Maldonado, C. Zuritz, and M. V. Assof, "Diffusion of glucose and sodium chloride in green olives during curing as affected by lye treatment," Journal of Food Engineering, vol. 84, no. 2, pp. 224-230, 2008.

[32] W. M. Walter, H. P. Fleming, and J. L. Etchells, "Preparation of antimicrobial compounds by hydrolysis of oleuropein from green olives," Applied Microbiology, vol. 26, pp. 773-776, 1973.

[33] P. Andrewes, J. Busch, T. De Joode, A. Groenewegen, and H. Alexandre, "Sensory properties of virgin olive oil polyphenols: identification of deacetoxy-ligstroside aglycon as a key contributor to pungency," Journal of Agricultural and Food Chemistry, vol. 51, no. 5, pp. 1415-1420, 2003.

[34] M. Esti, M. Contini, E. Moneta, and F. Sinesio, "Phenolics compounds and temporal perception of bitterness and pungency in extra-virgin olive oils: changes occurring throughout storage," Food Chemistry, vol. 113, no. 4, pp. 1095-1100, 2009.

[35] A. Piga, F. Gambella, V. Vacca, and M. Agabbio, "Response of three sardinian oliver cultivars to Greek-style processing," Italian Journal of Food Science, vol. 13, pp. 29-40, 2001.

[36] B. Antonio, H. Sánchez, P. G. García, and L. R. Navarro, "Trends in table olive production. Elaboration of table olives," Grasas Y Aceites, vol. 57, no. 1, pp. 86-94, 2006.

[37] N. Sabatini and V. Marsilio, "Volatile compounds in table olives (Olea europaea L., Nocellara del Belice cultivar)," Food Chemistry, vol. 107, no. 4, pp. 1522-1528, 2008.

[38] N. Sabatini, M. R. Mucciarella, and V. Marsilio, "Volatile compounds in uninoculated and inoculated table olives with Lactobacillus plantarum (Olea europaea L., cv. Moresca and Kalamata)," LWT-Food Science and Technology, vol. 41, no. 10, pp. 2017-2022, 2008.

[39] A. Piga, A. Del Caro, I. Pinna, and M. Agabbio, "Anthocyanin and colour evolution in naturally black table olives during anaerobic processing," LWT-Food Science and Technology, vol. 38, no. 4, pp. 425-429, 2005.

[40] D. Boskou, S. Camposeo, and M. L. Clodoveo, Table Olives as Sources of Bioactive Compounds. Olive and Olive Oil Bioactive Constituents, AOCS Press, Urbana, IL, USA, 2014.

[41] B. Lanza and F. L. Amoruso, "Sensory analysis of natural table olives: Relationship between appearance of defect and gustatory-kinaesthetic sensation changes," LWT-Food Science and Technology, vol. 68, pp. 365-372, 2016.

[42] M. Kotzekidou and M. Psani, "Technological characteristics of yeast strains and their potential as starter adjuncts in Greekstyle black olive fermentation," World Journal of Microbiology and Biotechnology, vol. 22, no. 12, pp. 1329-1336, 2006.

[43] C. S. Parinos, C. D. Stalikas, T. S. Giannopoulos, and G. Pilidis, "Chemical and physicochemical profile of wastewaters produced from the different stages of Spanish-style green olives processing," Journal of Hazardous Materials, vol. 145, no. 1-2, pp. 339-343, 2007.

[44] International Olive Oil Council, Trade Standard Applying to Table Olives, International Olive Oil Council, Madrid, Spain, 2004, http://www.internationaloliveoil.org/.

[45] R. Ambra, F. Natella, C. Bello, S. Lucchetti, V. Forte, and G. Pastore, "Phenolics fate in table olives (Olea europaea L. cv. Nocellara del Belice) debittered using the Spanish and 
Castelvetrano methods," Food Research International, vol. 100, pp. 369-376, 2017.

[46] F. N. Arroyo-López et al., "Formation of lactic acid bacteriayeasts communities on the olive surface during Spanish-style Manzanilla fermentations," Food Microbiology, vol. 32, no. 2, pp. 295-301, 2012.

[47] M. Brenes and A. de Castro, "Transformation of oleuropein and its hydrolysis products during Spanish-style green olive processing," Journal of the Science of Food and Agriculture, vol. 77, no. 3, pp. 353-358, 1998.

[48] A. Jime, R. Guille, and J. Ferna, "Factors affecting the 'Spanish Green Olive' process: their influence on final texture and industrial losses," Journal of Agricultural and Food Chemistry, vol. 45, no. 10, pp. 4065-4070, 1997.

[49] L. Cocolin, V. Alessandria, C. Botta et al., " $\mathrm{NaOH}$-debittering induces changes in bacterial ecology during table olives fermentation," PLoS One, vol. 8, no. 7, Article ID e69074, 2013.

[50] E. Medina, A. Garcia, C. Romero, A. Castro, and M. Brenes, "Study of the anti-lactic acid bacteria compounds in table olives," International Journal of Food Science and Technology, vol. 44, no. 7, pp. 1286-1291, 2009.

[51] C. Romero, A. García, E. Medina, M. V. Ruíz-Méndez, A. de Castro, and M. Brenes, "Triterpenic acids in table olives," Food Chemistry, vol. 118, no. 3, pp. 670-674, 2010.

[52] A. Montaño, F. J. Casado, A. Castro, A. H. Sánchez, and L. Rejano, "Influence of processing, storage time, and pasteurisation upon the tocopherol and amino acid contents of treated green table olives," European Food Research and Technology, vol. 220, no. 3-4, pp. 255-260, 2004.

[53] A. Bevilacqua, M. Cannarsi, M. Gallo, M. Sinigaglia, and M. Corbo, "Characterization and implications of Enterobacter cloacae strains isolated from Italian table olives 'Bella Di Cerignola', Journal of Food Science, vol. 75, no. 1, pp. 53-60, 2010.

[54] P. De Bellis, F. Valerio, A. Sisto, S. L. Lonigro, and P. Lavermicocca, "Probiotic table olives: microbial populations adhering on olive surface in fermentation sets inoculated with the probiotic strain Lactobacillus paracasei IMPC2.1 in an industrial plant," International Journal of Food Microbiology, vol. 140, no. 1, pp. 6-13, 2010.

[55] A. Kumral, M. Korukluoglu, C. Romero, A. de Castro, J. L. Ruiz-Barba, and M. Brenes, "Phenolic inhibitors involved in the natural fermentation of Gemlik cultivar black olives," European Food Research and Technology, vol. 236, no. 1, pp. 101-107, 2012.

[56] E. Medina, C. Romero, M. Brenes, P. García, A. de Castro, and A. García, "Profile of anti-lactic acid bacteria compounds during the storage of olives which are not treated with alkali," European Food Research and Technology, vol. 228, no. 1, pp. 133-138, 2008.

[57] A. I. Doulgeraki, P. Pramateftaki, A. A. Argyri, G.-J. E. Nychas, C. C. Tassou, and E. Z. Panagou, "Molecular characterization of lactic acid bacteria isolated from industrially fermented Greek table olives," LWT-Food Science and Technology, vol. 50, no. 1, pp. 353-356, 2013.

[58] V. Romero-Gil, J. Bautista-Gallego, F. Rodríguez-Gómez et al., "Evaluating the individual effects of temperature and salt on table olive related microorganisms," Food Microbiology, vol. 33, no. 2, pp. 178-184, 2013.

[59] E. Z. Panagou, U. Schillinger, C. M. A. P. Franz, and G. J. E. Nychas, "Microbiological and biochemical profile of cv. Conservolea naturally black olives during controlled fermentation with selected strains of lactic acid bacteria," Food Microbiology, vol. 25, no. 2, pp. 348-358, 2008.
[60] G. Bisignano, A. Tomaino, R. Lo Cascio, G. Crisafi, N. Uccella, and A. Saija, "On the in-vitro antimicrobial activity of oleuropein and hydroxytyrosol," Journal of Pharmacy and Pharmacology, vol. 51, no. 8, pp. 971-974, 1999.

[61] E. Medina, M. Brenes, C. Romero, A. García, and A. De Castro, "Main antimicrobial compounds in table olives," Journal of Agricultural and Food Chemistry, vol. 55, no. 24, pp. 9817-9823, 2007.

[62] F. N. Arroyo-López, V. Romero-Gil, J. Bautista-Gallego et al., "Yeasts in table olive processing: desirable or spoilage microorganisms?," International Journal of Food Microbiology, vol. 160, no. 1, pp. 42-49, 2012.

[63] M. Aponte, V. Ventorino, G. Blaiotta et al., "Study of green Sicilian table olive fermentations through microbiological, chemical and sensory analyses," Food Microbiology, vol. 27, no. 1, pp. 162-170, 2010.

[64] R. S. A. Alvarez, "Causative factor of "Floaters" during the curing of olives," Journal of Bacteriology, vol. 12, no. 5, pp. 359-365, 1926.

[65] G. Ciafardini, B. A. Zullo, and G. Cioccia, "Effect of lipaseproducing yeast on the oily fraction of microbiologically debittered table olives," European Journal of Lipid Science and Technology, vol. 107, no. 12, pp. 851-856, 2005.

[66] R. H. Vaughn, K. E. Stevenson, and B. A. Dave, "Fermenting yeasts associated with softening and gas-pocket formation in olives," Applied Microbiology, vol. 23, pp. 316-320, 1972.

[67] S. Charoenprasert and A. Mitchell, "Influence of Californiastyle black ripe olive processing on the formation of acrylamide," Journal of Agricultural and Food Chemistry, vol. 62, no. 34, pp. 8716-8721, 2014.

[68] V. Marsilio, C. Campestre, and B. Lanza, "Phenolic compounds change during California-style ripe olive processing," Food Chemistry, vol. 74, no. 1, pp. 55-60, 2001.

[69] D. M. Georget, A. C. Smith, K. W. Waldron, and L. Rejano, "Effect of Californian process on the texture of Hojiblanca olive (Olea europaea L) harvested at different ripening stages," Journal of the Science of Food and Agriculture, vol. 83, no. 6, pp. 574-579, 2003.

[70] I. Mafra, A. S. Barros, and M. A. Coimbra, "Effect of black oxidising table olive process on the cell wall polysaccharides of olive pulp (Olea europaea L. var. Negrinha do Douro)," Carbohydrate Polymers, vol. 65, no. 1, pp. 1-8, 2006.

[71] K. A. Segovia-Bravo, M. Jarén-Galán, P. García-García, and A. Garrido-Fernández, "Browning reactions in olives: mechanism and polyphenols involved," Food Chemistry, vol. 114, no. 4, pp. 1380-1385, 2009.

[72] M. Brenes-Balbuena, P. Garcia-Garcia, and A. GarridoFernández, "Phenolic compounds related to the black color formed during the processing of ripe olives," Journal of Agricultural and Food Chemistry, vol. 40, no. 7, pp. 1192-1196, 1992.

[73] M. Brenes, C. Romero, P. Garcia, and A. G. Fernfindez, "Catalytic effect of metal cations on the darkening reaction in ripe olive processing," Zeitschrift für Untersuchung von Lebensmitteln und Verbrauchsgegenständen, vol. 201, no. 3, pp. 221-225, 1995.

[74] F. J. Casado, A. Montaño, D. Spitzner, and R. Carle, "Investigations into acrylamide precursors in sterilized table olives: evidence of a peptic fraction being responsible for acrylamide formation," Food Chemistry, vol. 141, no. 2, pp. 1158-1165, 2013.

[75] F. J. Casado, A. H. Sánchez, and A. Montaño, "Reduction of acrylamide content of ripe olives by selected additives," Food Chemistry, vol. 119, no. 1, pp. 161-166, 2010. 
[76] S. M. Lee, K. Kitsawad, A. Sigal, D. Flynn, and J. X. Guinard, "Sensory properties and consumer acceptance of imported and domestic sliced black ripe olives," Journal of Food Science, vol. 77, no. 12, pp. S439-S448, 2012.

[77] A. Sansone-Land, G. R. Takeoka, and C. F. Shoemaker, "Volatile constituents of commercial imported and domestic black-ripe table olives (Olea europaea)," Food Chemistry, vol. 149, pp. 285-295, 2014.

[78] F. J. Benítez, J. L. Acero, T. González, and J. García, “Application of ozone and advanced oxidation processes to the treatment of lye-wastewaters from the table olives industry," Ozone: Science and Engineering, vol. 24, pp. 105-116, 2002.

[79] B. Gandul-rojas, M. Roca, and L. Gallardo-guerrero, "Detection of the color adulteration of green table olives with copper chlorophyllin complexes (E-141ii colorant)," LWTFood Science and Technology, vol. 46, no. 1, pp. 311-318, 2012.

[80] The Guardian, Green Olives Painted with Copper Sulphate Seized by Italian Police, The Guardian, London, UK, 2017, https://www.theguardian.com.

[81] E. Mousouri, E. Melliou, and P. Magiatis, "Isolation of megaritolactones and other bioactive metabolites from 'megaritiki' table olives and debittering water," Journal of Agricultural and Food Chemistry, vol. 62, no. 3, pp. 660-667, 2014.

[82] F. López, C. Romero, M. Quintana, A. López, P. García, and A. Fernández, "Kinetic study of the physicochemical and microbiological changes in 'seasoned' olives during the shelflife period," Journal of Agricultural and Food Chemistry, vol. 53, no. 13, pp. 5285-5292, 2005.

[83] E. Ramírez, P. García-García, A. De Castro, C. Romero, and M. Brenes, "Debittering of black dry-salted olives," European Journal of Lipid Science and Technology, vol. 115, no. 11, pp. 1319-1324, 2013.

[84] E. Panagou, "Greek dry-salted olives: monitoring the drysalting process and subsequent physico-chemical and microbiological profile during storage under different packing conditions at 4 and $20^{\circ} \mathrm{C}$," LWT-Food Science and Technology, vol. 39, no. 4, pp. 322-329, 2006.

[85] F. Mantzouridou and M. Z. Tsimidou, "Microbiological quality and biophenol content of hot air-dried Thassos cv. table olives upon storage," European Journal of Lipid Science and Technology, vol. 113, no. 6, pp. 786-795, 2011.

[86] Datamonitor, Study on the Promotion of Consumption of Olive Oil and Olives in the USA and Canada, Datamonitor, London, UK, 2010, http://www.datamonitor.com.

[87] United States Department of Agriculture, 2012 Census of Agriculture United States Summary and State Data, Vol. 1, Part 51, United States Department of Agriculture, Washington, DC, USA, 2014.

[88] P. Lazicki and D. Geisseler, Olive Production in California, California Department of Food and Agriculture, Fertilizer Research and Education Program (FREP), Sacramento, CA, USA, 2000, https://apps1.cdfa.ca.gov/FertilizerResearch/docs/ Olive_Production_CA.pdf.

[89] P. Pierantozzi, C. Zampini, M. Torres et al., "Physico-chemical and toxicological assessment of liquid wastes from olive processing-related industries," Journal of the Science of Food and Agriculture, vol. 92, no. 2, pp. 216-223, 2012.

[90] M. Habibi, M. Taghi, and G. Mesbahi, "Ultrasoundaccelerated debittering of olive fruits," Innovative Food Science and Emerging Technologies, vol. 31, pp. 105-115, 2015.

[91] C. E. Tamer, B. Incedayi, and B. Yildiz, "The use of vacuum impregnation for debittering green olives," Food Bioprocess Technology, vol. 6, no. 12, pp. 3604-3612, 2013.
[92] V. G. Dourtoglou, A. Mamalos, D. P. Makris, and P. Kefalas, "Storage of olives (Olea europaea L.) under $\mathrm{CO}_{2}$ atmosphere: liquid chromatography-mass spectrometry characterization of indices related to changes in polyphenolic metabolism," Journal of Agricultural and Food Chemistry, vol. 54, no. 6, pp. 2211-2217, 2006.

[93] E. Ramírez, P. García, M. Brenes, and C. Romero, "Evaluation of chemical components of debittered olives undergone preservation and polyphenol oxidation," International Journal of Food Science and Technology, vol. 51, no. 7, pp. 16741679, 2016.

[94] S. Tuna and A. Akpinar-Bayizit, "The use of $\beta$-glucosidase enzyme in black table olives fermentation," Notulae Botanicae Horti Agrobotanici Cluj-Napoca, vol. 37, no. 2, pp. 182-189, 2009.

[95] F. Rodríguez-Gómez, J. Bautista-Gallego, V. Romero-Gil, F. N. Arroyo-López, A. Garrido-Fernández, and P. GarcíaGarcía, "Effects of salt mixtures on Spanish green table olive fermentation performance," LWT-Food Science and Technology, vol. 46, no. 1, pp. 56-63, 2012.

[96] E. Tsantili, M. Kafkaletou, P. A. Roussos, and M. V. Christopoulos, "Phenolic compounds, maturation and quality in fresh green olives for table use during exposure at $20^{\circ} \mathrm{C}$ after preharvest ReTain treatment," Scientia Horticulturae, vol. 140, pp. 26-32, 2012.

[97] K. Yousfi, J. Cayuela, and J. García, "Effect of temperature, modified atmosphere and ethylene during olive storage on quality and bitterness level of the oil," Journal of the American Oil Chemists' Society, vol. 86, no. 3, pp. 291-296, 2009.

[98] S. Lalas, V. Athanasiadis, O. Gortzi et al., "Enrichment of table olives with polyphenols extracted from olive leaves," Food Chemistry, vol. 127, no. 4, pp. 1521-1525, 2011. 


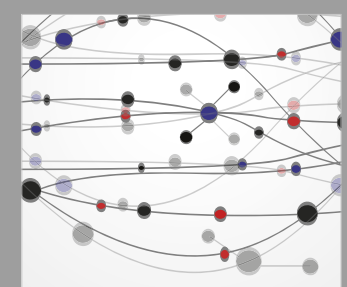

The Scientific World Journal
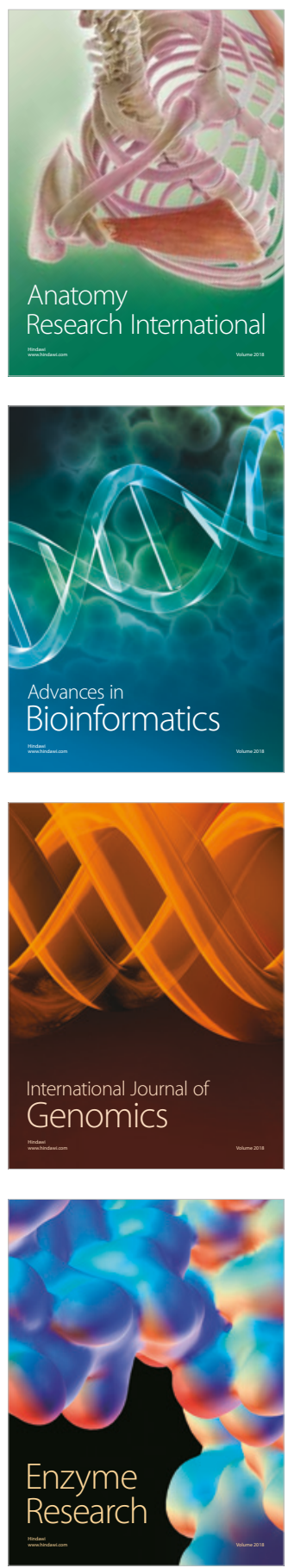
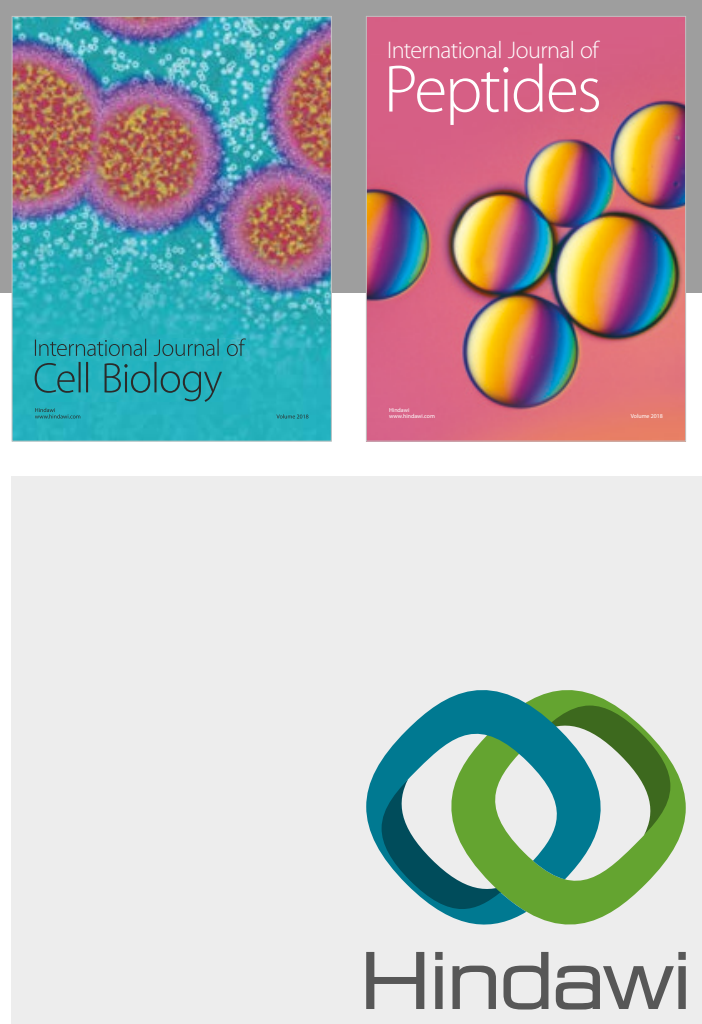

Submit your manuscripts at

www.hindawi.com
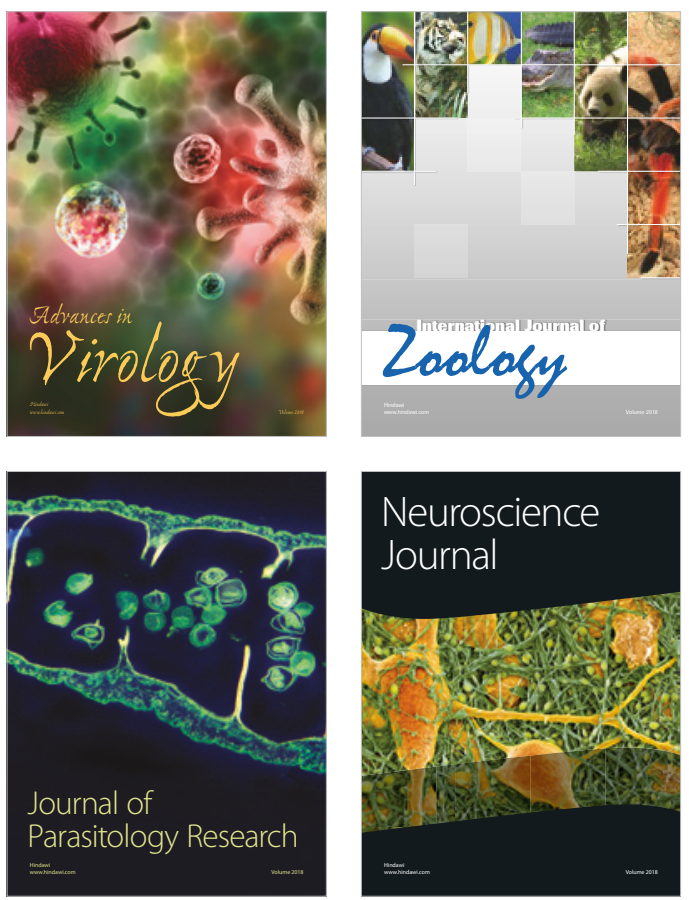
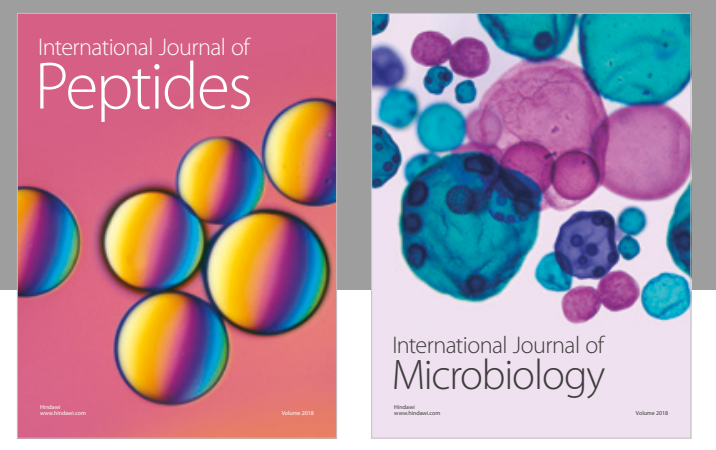

nternational Journal of Microbiology
Journal of
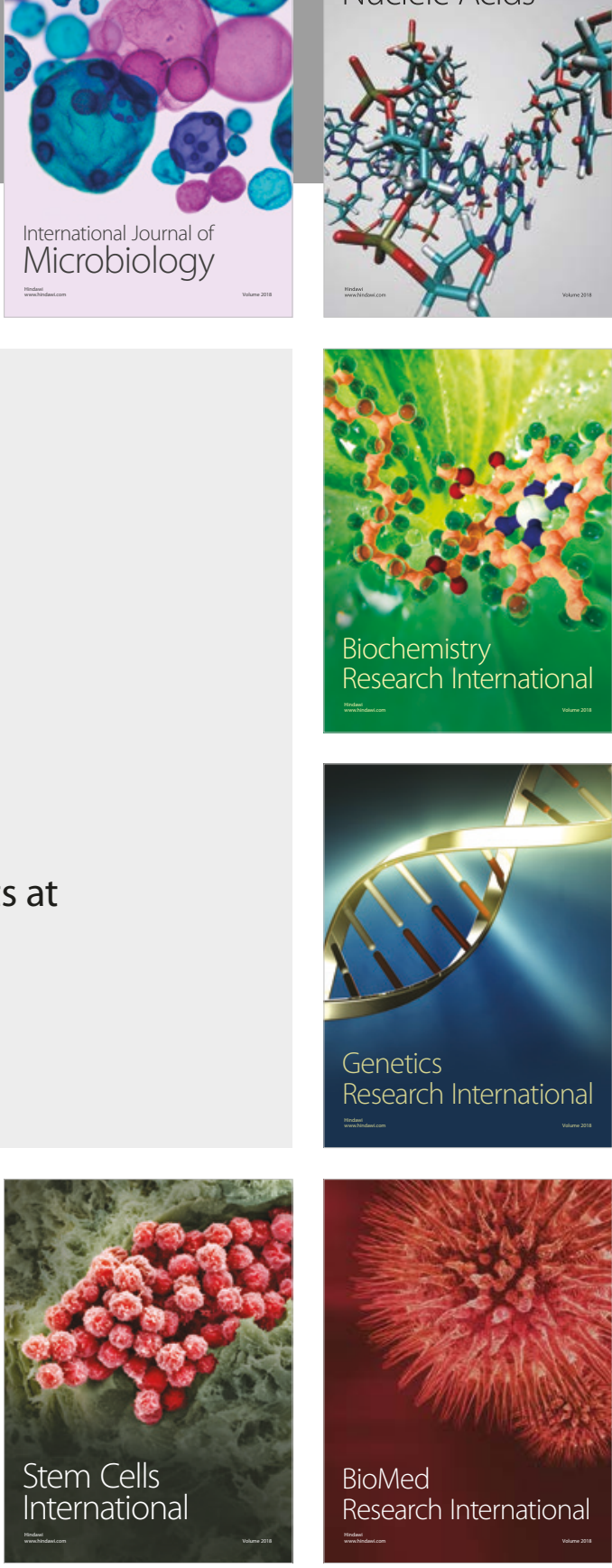
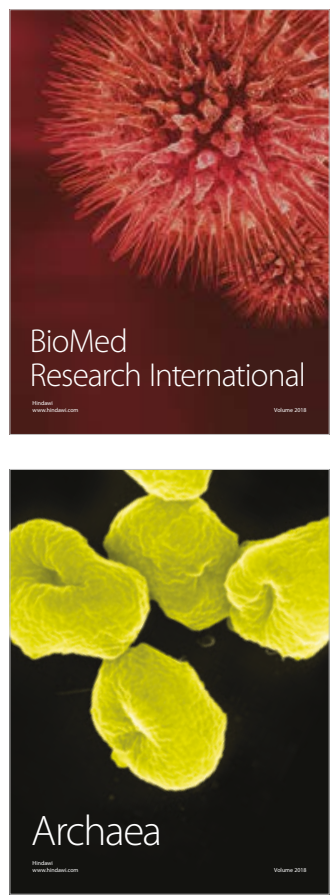